\title{
Understanding the Assessment of Oil Viscosity and Oil Recovery in Polymer Flooding Simulation
}

\author{
${ }^{1}$ Abubakar Bello, ${ }^{1}$ Alhassan Musa Obi and ${ }^{2}$ Musa Lawal \\ ${ }^{1}$ Department of Mineral \& Petroleum Resources Engineering \\ ${ }^{2}$ Department of Chemical Engineering \\ Kaduna Polytechnic, Kaduna-Nigeria
}

\begin{abstract}
This study aims to investigate the influence of oil viscosity on polymer flooding mechanism in one of the reservoirs of Bornu oil field using simulation model. The polymer flooding simulation is done by coding data of the selected field of study on a note pad and run on an Oil simulator ECLIPSE 100 and designed to investigate the behavior of oil viscosity sensitivity assessments on oil recovery. Results obtained from the simulations indicate that the FOPT, FOE, FCPT and FPR decrease with increase in the oil viscosity. These decreases are attributed to the increase in the mobility ratio between the polymer solution and the oil phase, the viscous forces are dominating, and the polymer solution underruns the oil, forming a so-called "gravity-tongue". The effect results in high proportion of the oil being left as residual oil at the end of the polymer flooding process. This study provides technical support in selecting and optimizing enhanced oil recovery systems for chemical flooding.
\end{abstract}

Keywords: Polymer flooding, Gravity-Tongue, Viscous Fingering, Oil recovery.

$\begin{array}{ll}\text { Abbreviations } \\ \text { EOR } & \text { Enhanced Oil Recovery } \\ \text { FOPT } & \text { Field Oil Production Total } \\ \text { FOE } & \text { Field Oil Efficiency } \\ \text { FPR } & \text { Field Pressure } \\ \text { FGOR } & \text { Field Gas Oil Ratio } \\ \text { FCPR } & \text { Field Polymer Production Rate } \\ \text { FCPT } & \text { Field Polymer Production Total } \\ \text { FWCT } & \text { Field Water Cut }\end{array}$

\section{INTRODUCTION}

EOR technology involves the injection of fluids that are initially not present in the reservoir to increase the recovery of oil from the reservoir that had been by-passed (Silset 2008). EOR uses about 15 different substances that are injected into the reservoir to mobilize substantial amount of oil to the production wells to increase the recovery of oil (Lake 2008; Taber 1997).

These chemicals are aimed at either altering the reservoir forces such as cappillary and viscous forces or fluids mobility properties such as viscosity. These forces greatly reduce recovery of oils by reducing mobility of oils due to high viscosities in either heavy or waxy oils and trapping by cappillary forces (Dongmei 2007; Lake 2008; Thomas 2008).

The chemical method is divided into three types based on the nature chemical added to the injected water that is into surfactant flooding, polymer flooding and caustic flooding (Amirbayov 2014).

Polymer flooding has been employed successfully in Daqing Oilfield in China for decades; it contributed to the oil recovery of more than $10 \%$ of original oil in place (OOIP) after water flooding (Wang et al. 2009).

As mentioned above polymer flooding improves recovery by mobility control and hence this is expresed mathematically using the mobility ratio as shown in the experimentally derived equation below (Dyes 1954).

M -Mobility ratio

$$
\mathrm{M}=\frac{\mathrm{k}_{\mathrm{w}} / \mu_{\mathrm{w}}}{\mathrm{k}_{\mathrm{o}} / \mu_{\mathrm{o}}}
$$

$\mathrm{k}_{\mathrm{w}}$-Effective permeability of water

$\mathrm{k}_{\mathrm{o}}$ - Effective permeability of oil

$\mu_{\mathrm{w}}$-Viscosity of water or the injected phase

$\mu_{\mathrm{o}}$-Viscosity of oil

From the equation above when mobility ratio $(\mathrm{M})$ is less than one, it predicts a stable displacement but above one, it predicts high possibility of unstable displacement due to viscous fingering that may arise because of high mobility of injected water.

The viscosity of the polymer solution which is the resistance of the solution to flow, is a key control to sweep efficiency and thus the recovery factor. As such controlling the effect of viscous fingering of the displacing fluid by piston like displacment mechanism (Abadli 2012; Dongmei 2007).

According to Dongmei (2007), the viscosity of polymer solution is controlled by three main factors; (1) the concentration of the polymer solution, (2) for this given type, the degree of HPAM-polymer hydrolysis and (3) the molecular weight of the polymer used which is also specific to a given polymer type and all the three are linearly related as in Figure.1 


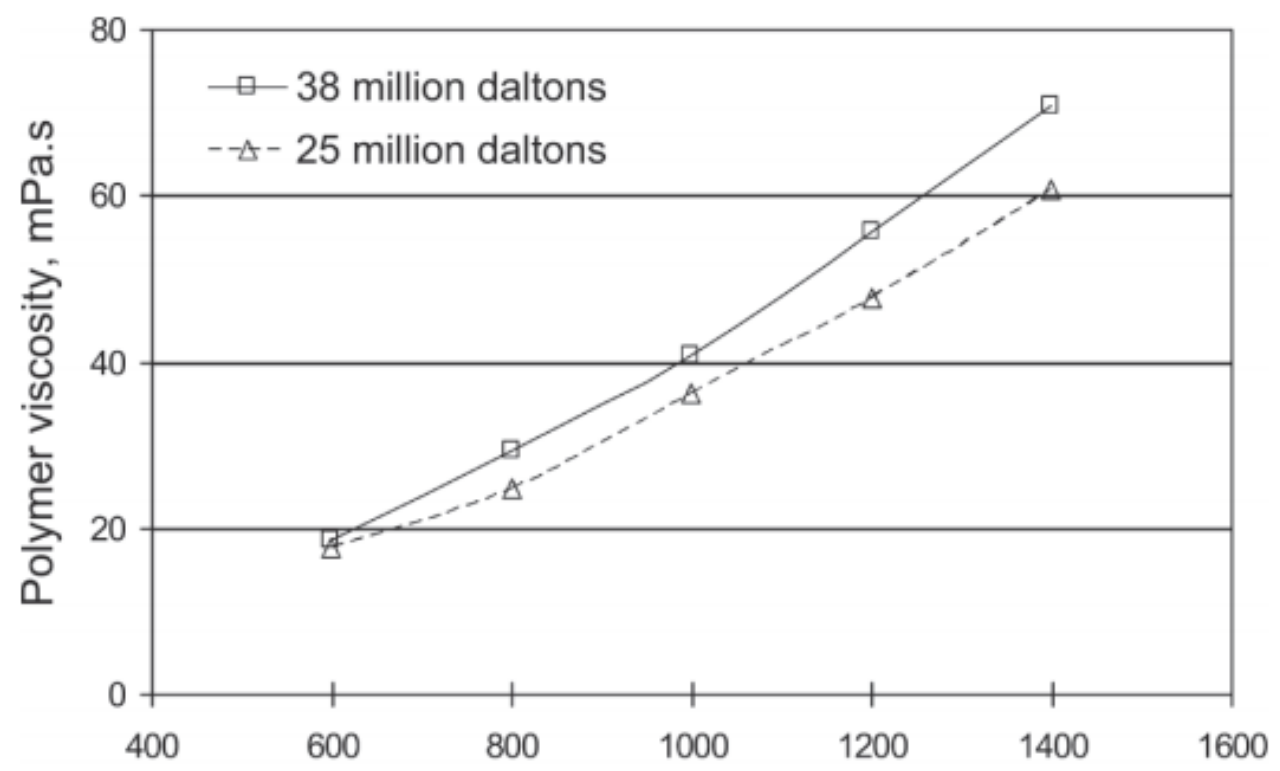

\section{Polymer concentration, $\mathrm{mg} / \mathrm{L}$}

Fig. 1: Variation viscosity with concentration and molecular weight of polymer used in making polymer solution (Dongmei 2007; Gao 2004).

Wax in crudes are high molecular weight, long chain hydrocrabons which maybe straight chain, branched or containing aromatic components that easily crystalize out of solution to form solids in crude at high temperatures for example the anticipated Chad oil Block one exploration area which are waxy having a pour point of $60^{\circ} \mathrm{C}$. Waxy crude are widely distributed in the globe and contributes greatly to high viscosity of some crude

Previous studies of waxy crude shows that properties such as API gravity, viscosity, molecular weight and wax appearance temperature shows direct linear relationships with wax content which is measured as the percentage weight of wax in the crude (Lalya M. ALghanduri 2010).

\section{EQUIPMENT AND MATERIALS}

The material used to conduct simulations in this work is a data from the XXX field in Chad/Borno Basin in a notepad under the different key words which are used for different functions run and Black Oil simulator model ECLIPSE Software 100.

The Polymer used is (modified polyacrylamide GLP-85) abbreviated as PAM) is a polymer $\left(-\mathrm{CH}_{2} \mathrm{CHCONH}_{2}-\right)$ formed from acrylamide subunits. It can be synthesized as a simple linear-chain structure or cross-linked, typically using $N, N$ '-methylenebisacrylamide. It is highly waterabsorbent, forming a soft gel when hydrated, non biological degraded. The common use of polyacrylamide and its derivatives is in subsurface applications such as Enhanced Oil Recovery. High viscosity aqueous solutions can be generated with low concentrations of polyacrylamide polymers and these can be injected to improve the economics of conventional water flooding and survive high temperature reservoirs. Thus, make it suitable for this project.<smiles>CCC(C)C(C)C(N)=O</smiles>

Fig.3. Courtesy en.wikipedia.org/wiki polyacrylamide)

\section{EXPERIMENTAL PROCEDURES}

This involves coding the geophysical, geological, and petroleum engineering data obtained from Integrated Data Services Limited (IDSL) a Subsidiary of Nigerian National Petroleum Corporation (NNPC) Nigeria in notepad under the different key words which are used for different functions. The numerical simulation of polymer flooding in Chad oil field is conducted using a Black Oil simulator, ECLIPSE 100 Reservoir simulator. This simulator is used to model flow of three phases, oil, water and gas as well as the complex processes of recovery predictions using polymer in a reservoir system.

The model grid is made of a rectangular coordinate system made up of $36 \times 51 \times 18$ cells with dimensions of $110 \times 205 \times 15 \mathrm{~m}$ but it actually consisted of 17 layers in $\mathrm{k}$ direction since the 1st layer was killed because it has nil porosity thus having 33048 cells in total. The geometry definition is given in a Petrel file name "MODEL_PETREL.GRDECL". Polymer flooding was carried out with assessment to investigate the influence of oil viscosity and polymer flooding on oil recovery efficiency 
in one of the reservoirs of Bornu oil field using simulation model.

The oil viscosity sensitivity study was carried out by varying in the range $4 \mathrm{cp}$ to $20 \mathrm{cp}$ as detailed in Table 1 below.

\section{RESULTS AD DISCUSSIONS}

From figure 1 and 2, the FOPT and FOE decreases with increase in the oil viscosity. This decrease in FOPT is attributed to the increase in the mobility ratio between the polymer solution and the oil phase, and tends to resist displacement by the polymer phase as such resulting into unstable polymer flood front causing viscous fingering.

From figure 3, the FCPT is high and increases more rapidly for low viscosity crude oil than for high viscosity crude. These may be due to high retention and entrapment of polymer by the high viscosity oils since it requires a high driving force for the oil to flow thus leaving substantial amount of polymer being retained in the reservoir.

From figure 4, despite the fact that low FOE recovery from high viscosity crudes, the FPR drop remained high enough to still sustain fluid recovery but this was also characterized by gradual average field pressure drop and rise with further increase in oil viscosity.

This result in uneven pressure distribution is as a result of delayed response to flow due to high viscosity of the oil and that the initial pressure applied to the oil is first utilize to overcome flow resistance basically internal forces within the fluid. These could also be due to effects of streamline flow of the injected phase that could be easily achieved when the oil phase has lower oil viscosity as compared with that of high viscosity crude oil as in figure 5 and 6 , regions indicated by the Blue Square of layer 4 for figure 5 and 6 respectively.

In figure 5, the streamline flow was more pronounced than for figure 6 at the end of the simulation run.

\section{CONCLUSIONS}

Increase in oil viscosity decreases the recovery efficiency logarithmically. Therefore, increase in waxy content of oil has similar effect on oil recovery.

Table 1: Showing viscosities of oil used in oil viscosity sensitivity assessment

\begin{tabular}{|c|c|}
\hline \multicolumn{1}{|c|}{ Case } & Oil viscosity (cp) \\
\hline Case 1 & 4.341 \\
\hline Case 2 & 10.129 \\
\hline Case 3 & 20.258 \\
\hline
\end{tabular}

Table 2: Summary of the simulation results of all the three cases of the oil viscosity sensitivity

\begin{tabular}{|l|c|c|c|c|c|c|c|}
\hline & $\begin{array}{c}\text { Oil viscosity } \\
(\mathbf{c p})\end{array}$ & $\begin{array}{c}\text { Mobility } \\
\text { Ratio }\end{array}$ & FOE $(\%)$ & $\begin{array}{c}\text { FOPT } \\
\left(\mathbf{x 1 0}^{6} \text { Stm }^{3}\right)\end{array}$ & $\begin{array}{c}\text { FCPT } \\
(\text { kg) }\end{array}$ & $\begin{array}{c}\text { Maximum } \\
\text { FWCT }\end{array}$ & $\begin{array}{c}\text { Maximum } \\
\text { FWCT Time } \\
(\text { year })\end{array}$ \\
\hline Case 1 & 4.341 & $\mathbf{0 . 1 8 2}$ & $\mathbf{1 2 . 3 7 2}$ & $\mathbf{4 . 4 0 8 2}$ & $\mathbf{1 9 1 0 6 0}$ & $\mathbf{0 . 9 0 0}$ & $\mathbf{1 8 . 4 3 9}$ \\
\hline Case 2 & $\mathbf{1 0 . 1 2 9}$ & $\mathbf{0 . 4 2 6}$ & $\mathbf{9 . 0 3 1}$ & $\mathbf{3 . 2 1 4 3}$ & $\mathbf{1 4 3 0 5 3}$ & $\mathbf{0 . 9 0 0}$ & $\mathbf{2 0 . 0 0}$ \\
\hline Case 3 & $\mathbf{2 0 . 2 5 8}$ & $\mathbf{0 . 8 5 1}$ & $\mathbf{6 . 4 5 4}$ & $\mathbf{2 . 3 0 6 1}$ & $\mathbf{7 9 4 0 8}$ & $\mathbf{0 8 7 2}$ & $\mathbf{2 0 . 0 0}$ \\
\hline
\end{tabular}




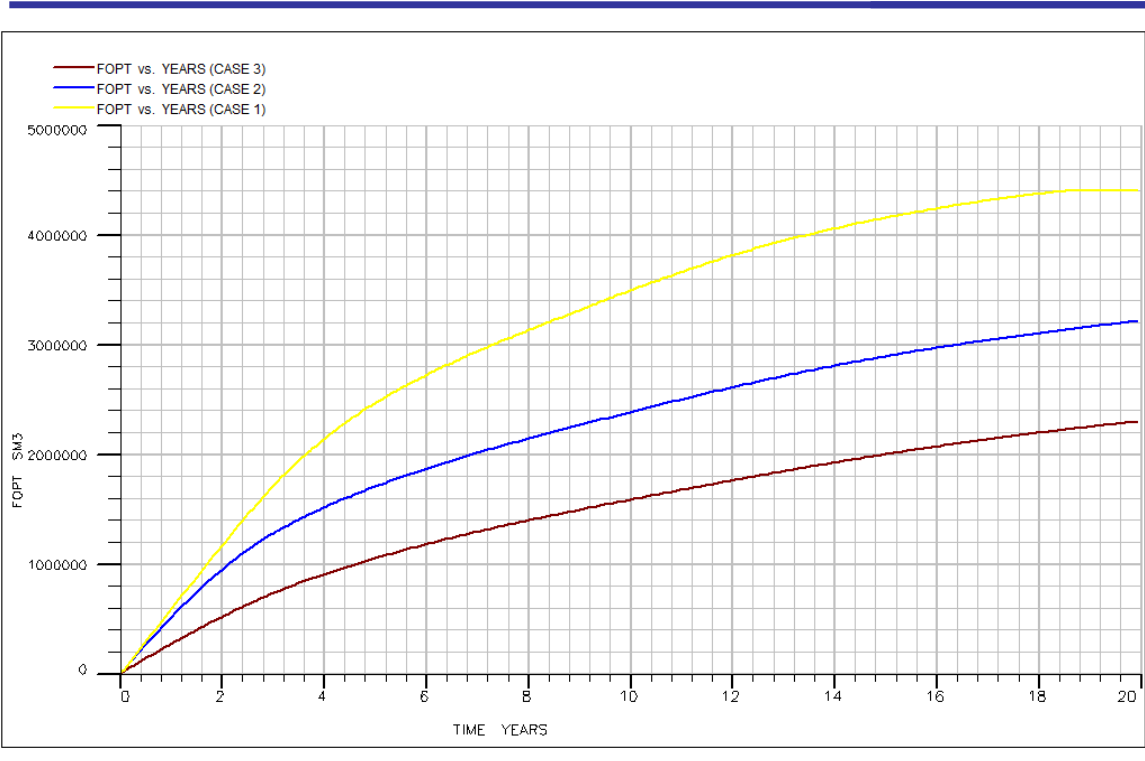

Fig.1: FOPT as a function of time for all the cases of oil viscosity sensitivity studies

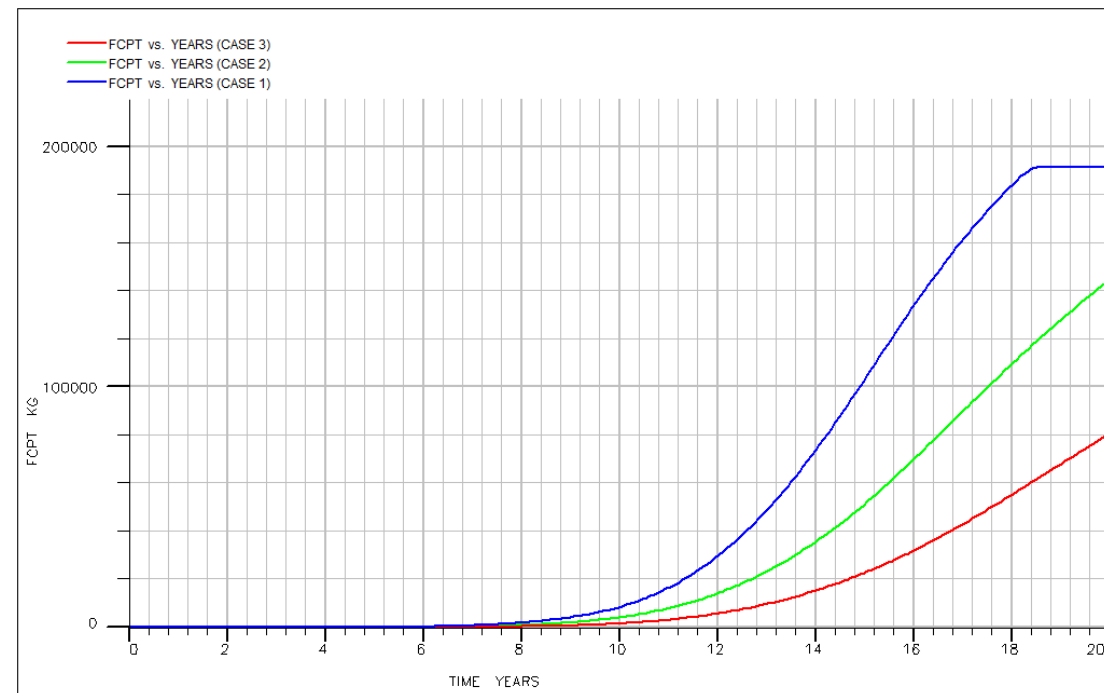

Fig. 3: Plot of FCPT against time for all the three cases

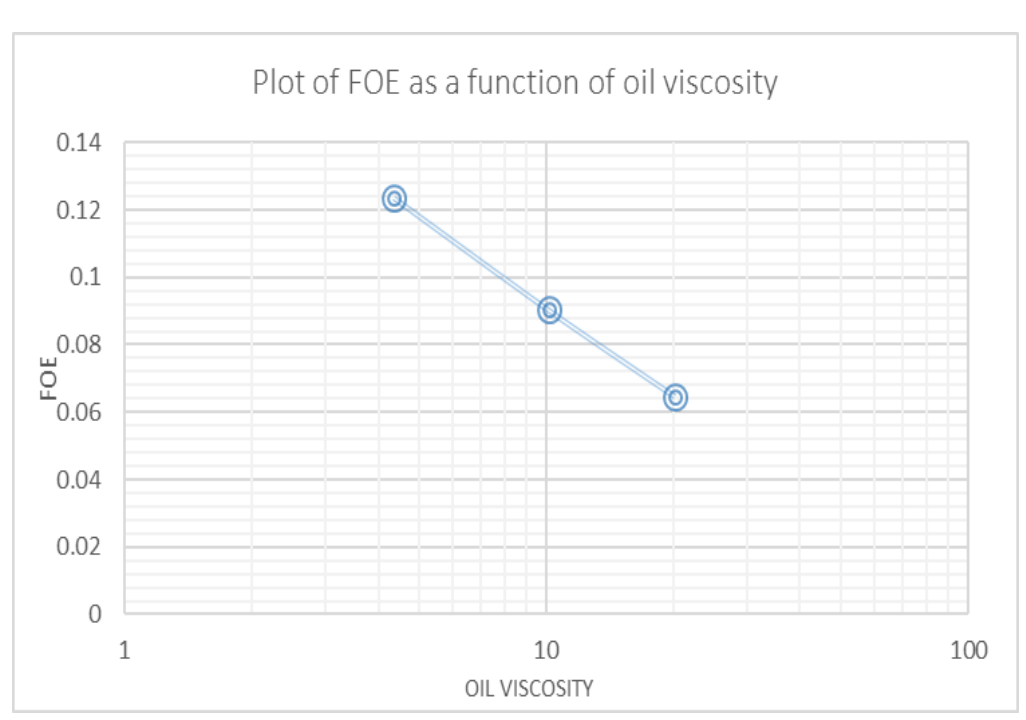

Fig.2: Plot of FOE from simulation against oil viscosity

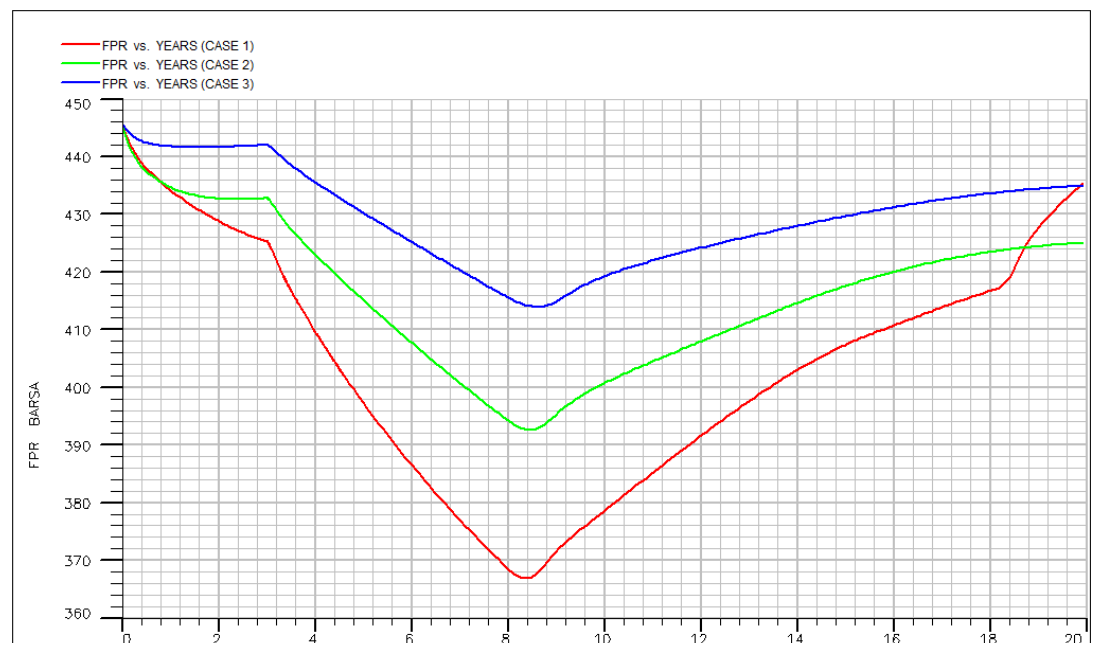

Fig. 4: Plot of FPR as function of time for all the three cases of viscosity sensitivity 


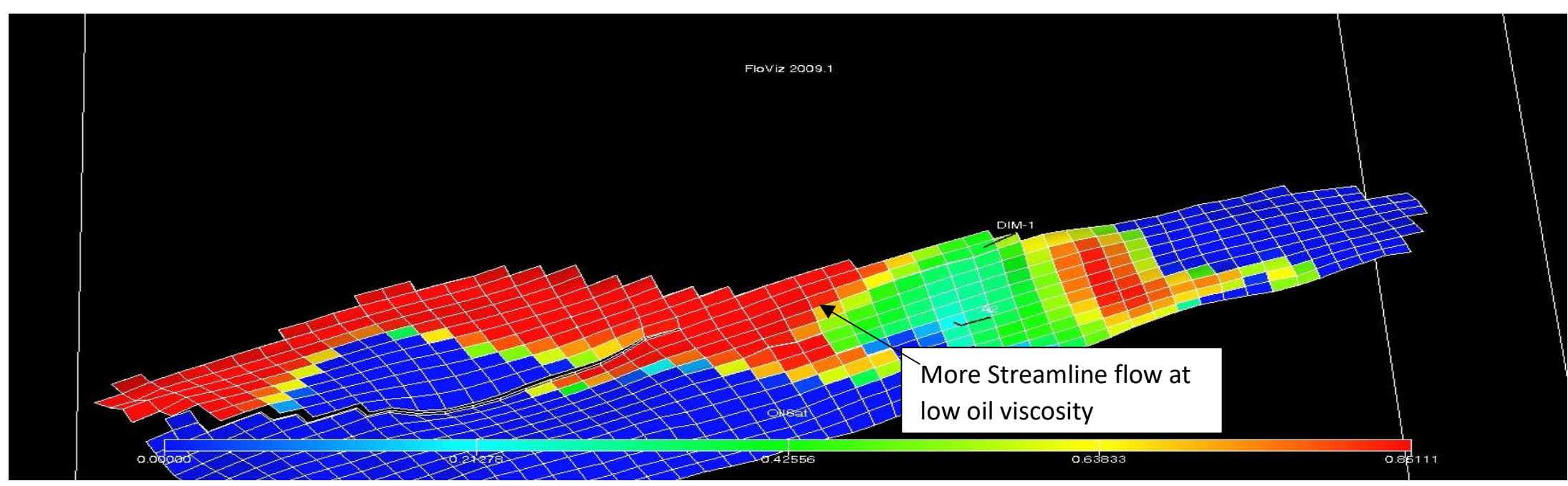

Fig. 5: Floviz image of layer 4 showing effect of streamline flow on FCPT

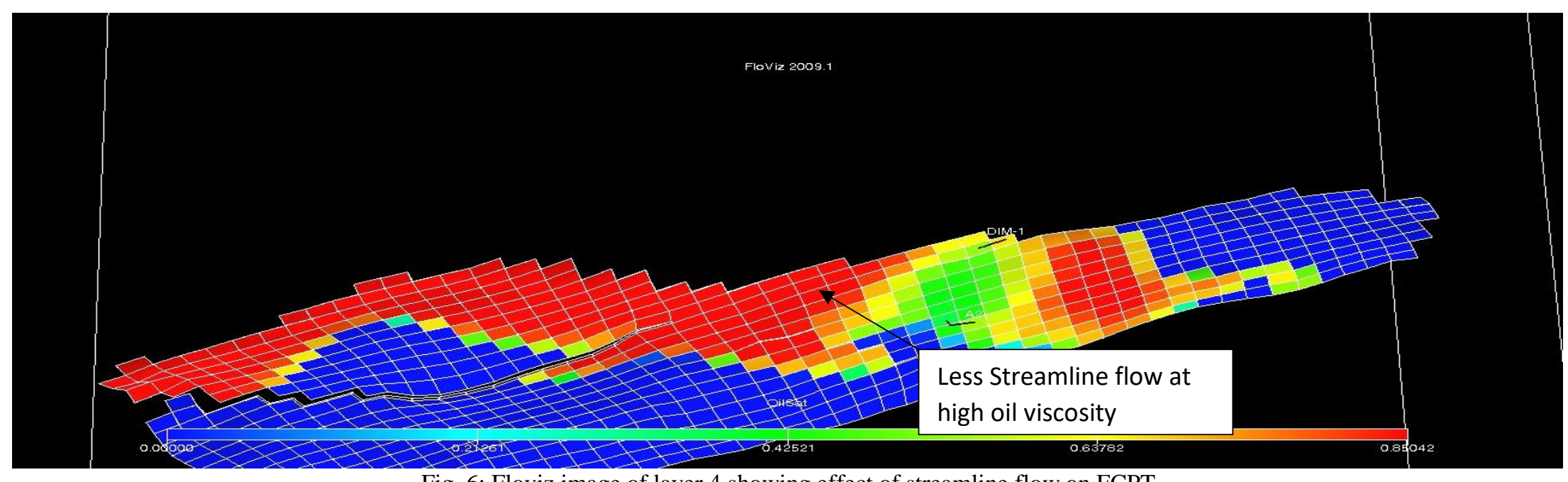

Fig. 6: Floviz image of layer 4 showing effect of streamline flow on FCPT 


\section{REFERENCES}

[1] Abadli, Farid (2012), 'Simulation Study of Enhanced Oil Recovery by ASP (Alkaline, Surfactant and Polymer) Flooding for Norne Field C-segment', (Norwegian University of Science and Technology).

[2] Amirbayov, Teyyub (2014), 'Simulation Study of the Polymer Flooding Applied to the Norne Field E-Segment', Master's thesis (Norwegian University of Science and Technology).

[3] Dongmei, W, Seright, RS Zhenbo, S, and Jinmei, W, (2007), 'Key Aspects of Project Design for Polymer Flooding', SPE Annual Technical Conference and Exhibition. (California, U.S.A.: SPE International).

[4] Dyes, A. B Caudle, B. H and Erickson, R. A. (1954), 'Oil Production After Breakthrough as Influenced by Mobility Ratio', Journal of Petroleum Technology, 6 (4), 27 - 32.

[5] Gao, S, and Su, Y. (2004), 'The development project design of polymer flooding for the central Xing4-5 in Daqing', Yearly report, 12, 16-17.

[6] Lalya M. ALghanduri, Mohamed M. Elgarni, John Luc Daridon and Joao A. P. Coutinho (2010), 'Characterization of Libyan Waxy Crude Oils', Energy Fuels, 24, 3101-07.
[7] Lake, Dr, Larry, W. and Walsh, Dr, Mark, P. (2008), 'Enhanced Oil Recovery (EOR) Field Data Literature Search', (AustinTexas: University of Texas Austin), 1-112.

[8] Silset, Anne (2008), 'Emulsions (w/o and o/w) of Heavy Crude Oils. Characterization, Stabilization, Destabilization and Produced Water Quality', (Norwegian University of Science and Technology).

[9] Taber, J. J. Martin, F.D and Seright, R.S. (1997), 'EOR Screening Criteria Revisited-Part 1: Introductionto Screening Criteria and Enhanced Recovery Field Projects', SPWDOE ImprovedOil RecoverySymposium (Tulsa, Oklahoma: SPE Reservoir Engineering).

[10] Thomas, S. (2008), 'Enhanced Oil Recovery-Review', IFP International Conference (63; Canada: Oil \& Gas Science and Technology), 9-19.

[11] Wang D, Dong H, Lv C, Fu X, Nie J (2009) Review of practical experience by polymer flooding at Daqing. SPE Reserve Eval Eng 12(3):470-476 